\title{
A novel Carbon Capture and Utilisation concept applied to the ceramic industry
}

\author{
Roberto Saponelli ${ }^{1}$, Massimo Milani ${ }^{1}$, Luca Montorsi $^{1, *}$, Bianca Rimini $^{1}$, Matteo \\ Venturelli ${ }^{1}$, Stefano Stendardo ${ }^{2}$, and Vincenzo Barbarossa ${ }^{2}$ \\ ${ }^{1}$ Department of Sciences and Methods for Engineering, University of Modena and Reggio Emilia, \\ Italy. \\ ${ }^{2}$ ENEA - Department of Energy Technologies (Rome) Italy
}

\begin{abstract}
This paper investigates a new concept for the $\mathrm{CO}_{2}$ emission mitigation in the ceramic industry based on carbon reduction and methane formation. The concept is analysed as a retrofit to the natural gas fuelled ceramic kiln that represents the main responsible of this industry in terms of energy consumption and exhaust emissions. The carbon dioxide conversion to methane is obtained by reduction with hydrogen on a Ni catalyst and thus methane is used to fuel the standard burners that equip the kiln. The paper addresses different sources for the hydrogen used as a feedstock for the proposed concept as well as alternative catalysts are explored and compared in terms of reduction efficiency and costs. A lumped and distributed parameter simulation of the entire ceramic kiln is combined to the CFD simulation of the reactor to estimate the efficiency of the $\mathrm{CO}_{2}$ reduction and the corresponding methane production for a reference ceramic kiln. The results of the numerical simulations are then employed to discuss the potential benefits of the proposed concept in terms of carbon dioxide emission reduction for the ceramic production. An economic assessment of the system analysed is also carried out concept to determine the investment necessary to implement the technology in an existing ceramic kiln. The potential replicability for other industrial sector is also addressed.
\end{abstract}

\section{Introduction}

The ceramic industry is well known to be characterized by energy intense processes and among them, the ceramic firing in the kiln is one of the main responsible of the primary energy consumption. Recent regulations for the energy consumption limit the fuel or electricity use [1] and therefore, the design of the kiln plays a fundamental role in meeting the regulations' requirements. Furthermore, the environmental concerns drive the design towards cleaner systems and more stringent limits about the pollutant emissions. In [2] improvements to the firing and pressing processes were proposed by means of a LCA approach. In [3] it was identified that the firing and drying processes are the main

\footnotetext{
*Corresponding author: luca.montorsi@unimore.it
} 
responsible for the $\mathrm{CO}_{2}$ emissions in the ceramic industry since mainly fossil fuels are adopted for powering them.

In this paper a new concept for the $\mathrm{CO}_{2}$ emission mitigation in the ceramic industry based on carbon reduction and methane formation is investigated. The concept is analysed as a retrofit to the natural gas fuelled ceramic kiln that represents the main responsible of this industry in terms of energy consumption and exhaust emissions. The carbon dioxide conversion to methane is obtained by reduction with hydrogen on a $\mathrm{Ni}$ catalyst and thus methane is used to fuel the standard burners that equip the kiln.

Carbon dioxide is now considered an important source of carbon for the synthesis of organic and inorganic compounds. In particular, there is a growing interest around the possibility to treat the $\mathrm{CO}_{2}$ in a reducing environment to convert it to methanol or methane. In the framework of the novel $\mathrm{CO}_{2}$ utilization concept applied to the ceramic industry as discussed in this paper, our interest is focused in the conversion to methane according to the Sabatier's reaction, in which one mole of methane cab be obtained by the reaction of one mole of carbon dioxide and four moles of hydrogen.

$$
\mathrm{CO}_{2}+4 \mathrm{H}_{2} \leftrightarrows \mathrm{CH}_{4}+2 \mathrm{H}_{2} \mathrm{O}
$$

Hydrogenation of $\mathrm{CO}_{2}$ toward methane has been investigated using catalytic system based on supported VIII group metals (e.g. $\mathrm{Ru}, \mathrm{Rh}, \mathrm{Co}, \mathrm{Fe}, \mathrm{Ni}$ ) on various oxide supports $\left(\mathrm{Al}_{2} \mathrm{O}_{3}, \mathrm{TiO}_{2}, \mathrm{CeO}_{2}, \mathrm{MgO}, \mathrm{NiO}-\mathrm{MgAl}_{2} \mathrm{O}_{4}, \mathrm{NiO}-\mathrm{K}_{2} \mathrm{O}-\mathrm{MgAl}_{2} \mathrm{O}_{4}, \mathrm{SiO}_{2}, \mathrm{Cr}_{2} \mathrm{O}_{3}, \mathrm{ksr}, \mathrm{MgO}-\mathrm{ksr}\right.$, $\mathrm{ZrO}_{2}, \mathrm{Al}_{2} \mathrm{O}_{3}-\mathrm{CaO}, \mathrm{La}_{2} \mathrm{O}_{3}$ ) [4]. However, supported nickel catalysts remain the most widely studied materials due to its low cost and its good catalytic activity [5].

In this study a $\mathrm{Ni}$ based commercial type catalyst was used in a tubular plug flow reactor working at atmospheric pressure and up to the temperature of $750 \mathrm{~K}$.

The hydrogen required for the hydrogenation of the $\mathrm{CO}_{2}$ is obtained by a novel concept that exploits the aluminium reaction with water. Recently, many studies are investigating the reaction of metals with water to produce hydrogen and particular attention is devoted to the use of aluminium [6-11]. The system for hydrogen production employed for the present analysis is focused on the development of a new hydrogen and power production system based on the aluminium combustion with water as described in [11] and [12]. The system can be used for local hydrogen production by exploiting the aluminium water steam reaction and thus, instead of transporting and storing $\mathrm{H}_{2}$, aluminium is transported and accumulated. Both primary and secondary aluminium can be exploited in the system as well as scrap aluminium. The system by-product, i.e. the alumina, can be either sold in the market as a commodity or recycled back where the renewable energy source is available and retransformed into aluminium in a closed cycle.

\section{Materials and methods}

The proposed Carbon Capture and Utilisation technologies is based on two main systems: the carbon dioxide conversion to methane by reduction with hydrogen on a Ni catalyst and the hydrogen production by means of aluminium reaction with water. In the following the schematic and the functioning of the systems are depicted.

\subsection{Carbon dioxide conversion to methane}

A quartz tubular reactor (PFR) in ideal displacement conditions characterized by no longitudinal or lateral mixing in the stream of reacting gas was used. The catalyst was 
a BASF GI-85 containing $50 \%$ of $\mathrm{Ni}$ on $\mathrm{Al}_{2} \mathrm{O}_{3}$ pellets. All the experiments were carried out using $\mathrm{CO}_{2} / \mathrm{H}_{2}$ molar ratio at the stoichiometric value, i.e. $1 / 4$.

Prior each new experimental run, the catalyst was treated with hydrogen at $673 \mathrm{~K}$ for 4 hours, than the temperature was set to the given value and the $\mathrm{CO}_{2}$ was added.

In order to asses one of the critical aspects of the methanation process, i.e. the sulphur poisoning of the catalyst, $\mathrm{H}_{2} \mathrm{~S}\left(1 \%\right.$ in $\left.\mathrm{N}_{2}\right)$ was used.

The composition of the gaseous products of methanation reaction (1) has been calculated via a minimization of Gibbs free energy of the chemical components involved in the process.

The key hypotheses considered in the model are: (i) reactor is in steady state condition; (ii) chemical equilibrium the total free energy of the system has its minimum value; (iii) The reactor operates at isothermal conditions; (iv) Coke formation is neglected; (v) The used physical properties of the key chemical components are provided in the relative database. The thermodynamic model, is based on the Redlich-Kwong-Soave equation.

\subsection{Hydrogen production}

The hydrogen production facility proposed in this paper is based on the aluminium reaction with water at high temperature and ambient pressure [12-15]. The system is potentially able to produce continuously hydrogen, high temperature steam, heat and work at the turbine shaft, by the exploitation of the highly exothermal oxidation of aluminium with water steam (2).

$$
2 \mathrm{Al}(\mathrm{s})+3 \mathrm{H}_{2} \mathrm{O}(\mathrm{g}) \rightarrow \mathrm{Al}_{2} \mathrm{O}_{3}(\mathrm{~s})+3 \mathrm{H}_{2}(\mathrm{~g})+954.8 \mathrm{~kJ} / \mathrm{mol}(\mathrm{T}=298.15 \mathrm{~K} ; \mathrm{p}=1.00 \mathrm{~atm})
$$

In the standard use of aluminium for industrial components, the metal is passivated by an aluminium oxide layer. The system proposed in [12] can remove the layer of aluminium oxide from the aluminium surface producing particles of aluminium with an average dimension lower than $0.05 \mathrm{~mm}$. An alternative system for the aluminium oxide removal uses the aluminium melting and injects liquid $\mathrm{Al}$ in a stream of water steam.

The conceptual design as presented in [12] can be developed in a real hydrogen and electric power co-generation plant on the basis of the schematic of Figure 1.

The system exploits the thermal power of the AL- $\mathrm{H}_{2} \mathrm{O}$ combustion products to heat up an amount of water used in a superheated steam turbine cycle in a way similar to a traditional steam generator. The reacting water steam and the aluminium (either in solid particles or in a liquid state) mix in the combustor and combustion takes place; the amount of reacting water exceeds the stoichiometric value in order to limit the combustion temperature. The heat released during the combustion process is used to vaporize the working cycle water flowing through the wall tubes which cover the inner and outer walls of the combustion chamber (C.C.). These tubes are the first part of the evaporator of the steam generator (S.G.) located downstream of the combustor. In Figure L1, the continuous lines represent the flow through the combustion chamber, the dashed lines represent the operating fluid stream (i.e. water/steam), the dot/dashed lines represent the reacting water flow, the long dashed lines represent the aluminium that enters the C.C. and the dotted lines represent the solid aluminium oxide particles exiting the system. The separation of the aluminium oxide particles from the hydrogen/water gas mixture is carried out by means of a series of cyclones and pneumatic filters that have been considered as a part of the S.G. Under regular working conditions, after the start-up phase, a cold mixture of exhaust gases (i.e. a hydrogen fraction $\alpha$ and a water steam fraction $\beta$ ) is recycled back to reduce the global temperature within the combustion chamber (double dot/dashed line). The reacting 
water is collected from the turbine outlet; thus, the turbine has to be design with a downstream working pressure (i.e. 1.20 bar). Even though this solution is characterized by a lower value of the turbine output power, both the water mass flow through the S.G. and the heat necessary to vaporize the reacting water are definitely lower.

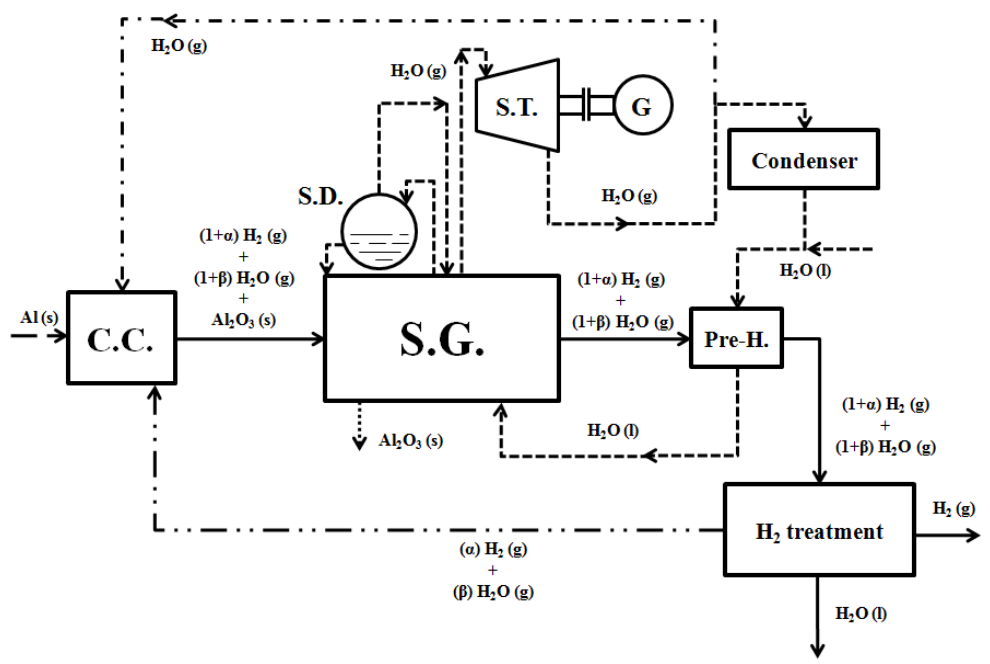

Fig. 1. Simplified system layout of the hydrogen - electric power cogeneration plant.

The components of the proposed system are derived from well-established technologies used in superheated steam cycle power plants; the only special part is obviously the combustor where the aluminium - water reaction occurs.

Within the scope of the technology proposed in this paper, the co-generation system presented above will be used for hydrogen production only. Thus, the focus of the hydrogen generation analysis will be on the combustion chamber and the technological challenges that need to be solved in order to exploit aluminium combustion with water to obtain $\mathrm{H}_{2}$ and aluminium oxide.

\section{Results and discussion}

First a numerical simulation of the methanation process is carried out. Figure 2 reports a parametric analysis with the change of the ratio $\mathrm{CO}_{2} / \mathrm{H}_{2}$ at different temperatures $\left(200^{\circ} \mathrm{C}\right.$, $300^{\circ} \mathrm{C}, 400^{\circ} \mathrm{C}, 500^{\circ} \mathrm{C}$ ) under 1 bar. The entering molar flow rate of $\mathrm{H}_{2}$ is fixed at $4 \mathrm{kmol} / \mathrm{h}$ and the $\mathrm{CO}_{2}$ molar flow rate is adjusted to the given ratio. The simulation confirms that maximum yield of $\mathrm{CH}_{4}$ is obtained at the stoichiometric ratio $\left(\mathrm{CO}_{2} / \mathrm{H}_{2}=0.25\right)$ and lower temperature $\left(200^{\circ} \mathrm{C}\right)$. With the increase of operating temperature, the maximum of the $\mathrm{CH}_{4}$ yield decreases ranging from $60 \% \mathrm{v} / \mathrm{v}\left(\mathrm{T}=200^{\circ} \mathrm{C}\right)$ down to $40 \% \mathrm{v} / \mathrm{v}\left(\mathrm{T}=500^{\circ} \mathrm{C}\right)$. With the increase of temperature, the $\mathrm{CH}_{4}$ content shows a smoother decrease whereas the $\mathrm{CO}$ increases with the increase of the $\mathrm{CO}_{2}$.

The content of $\mathrm{CO}$ at higher temperature and high $\mathrm{CO}_{2} / \mathrm{H}_{2}$ ratio (Panel (d)) is probably due to the reverse water gas shift reaction (2). The simulation results presented in Fig. 2 suggest to perform the experimental campaign at $\mathrm{T}=200^{\circ} \mathrm{C}$ and at stoichiometric conditions $\left(\mathrm{CO}_{2} / \mathrm{H}_{2}=0.25\right)$ where the dominant route for $\mathrm{CO}$ disappearance is the methanation reaction. 

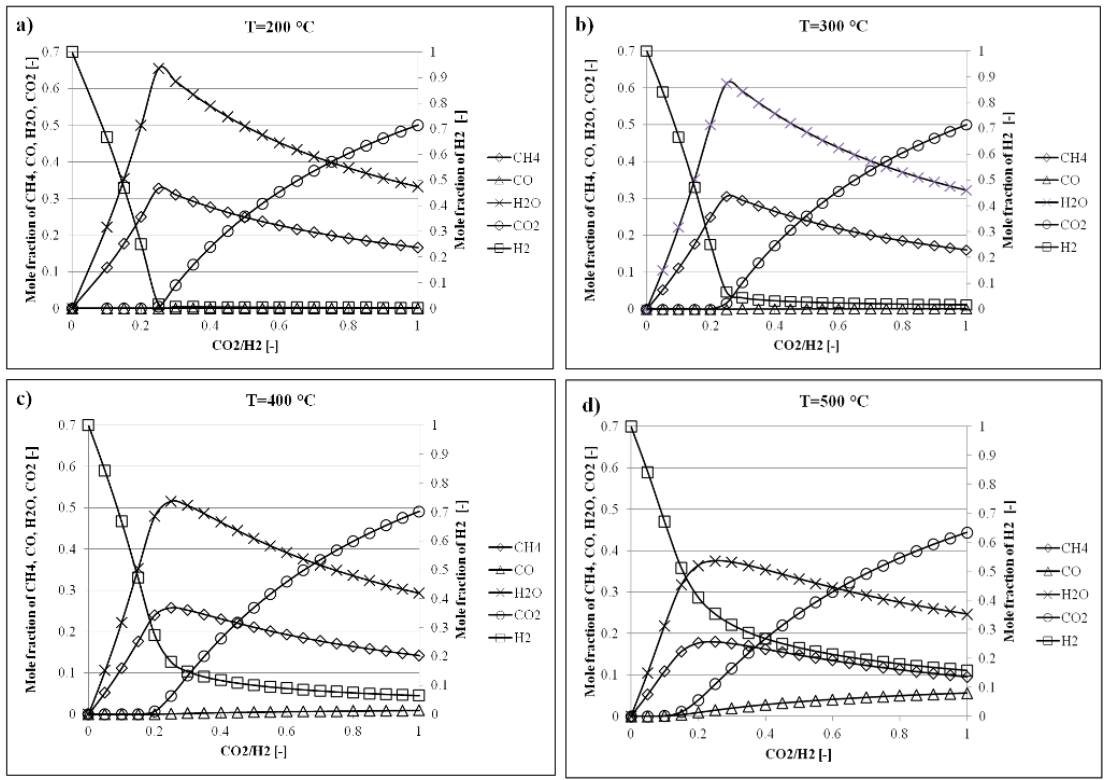

Fig. 2. Parametric analysis of methanation reaction.

At lower temperature another the dominant route of $\mathrm{CO}$ disappearance is the water gas shift making negligible the content of $\mathrm{CO}$ enhancing the production of methane.

$$
\mathrm{CO}+\mathrm{H}_{2} \leftrightarrows \mathrm{CO}+\mathrm{H}_{2} \mathrm{O}
$$

Laboratory scale experiments leads industrial size system highlights criticisms as catalysts deactivations (e.g. carbon deposition, sulphur poisoning, sintering). When the reactant gas mixtures was composed by $160 \mathrm{sccm}$ of $\mathrm{H}_{2}$ and $40 \mathrm{sccm}$ of $\mathrm{CO}_{2}$ and the pressure was one atmosphere, the methane conversion yield (i.e. the moles of produced methane over the moles of in-coming carbon dioxide) reported in the Figure 3 is observed. The catalyst was $0.392 \mathrm{~g}$ of GI-85.

As shown, the catalyst's activity starts at about $500 \mathrm{~K}$ and reaches the conversion yield of about $80 \%$ at $640 \mathrm{~K}$. At higher temperatures, the conversion yield decreases.

As the reaction proceeds a carbon layer deposits on the catalyst particles causes a catalytic activity decay. This type of catalyst deactivation is a reversible one that needs a hydrogen treatment to restore the pristine catalytic performances [16].

Sulphur poisoning instead results in an irreversible deactivation of the Ni metal surface [17]. The sulphur sensitivity is related to both the metal and the support materials [18]. $\mathrm{Ni}$ based catalysts undergo a severe deactivation when the feed gas contains $\mathrm{H}_{2} \mathrm{~S}$ as low as ppb level [19].

In a $\mathrm{Ni}$ catalyst constituted by $0.216 \mathrm{~g}$ of $\mathrm{Ni}$ dispersed in $0.624 \mathrm{~g}$ of rock wool we measure an initial methane conversion yield of $22 \%$ at the temperature of $550 \mathrm{~K}$ and pressure of $0.1 \mathrm{MPa}$ and space velocity of $4000 \mathrm{~h}^{-1}$. After hydrogen reduction at $553 \mathrm{~K}$ for $1 \mathrm{~h}$ at a space velocity of $2000 \mathrm{~h}^{-1}$ the methane conversion yield rises to $38 \%$. This catalyst after $22 \mathrm{~h}$ of work show a reduced yield of $13 \%$, due to the deposition of carbonaceous material on Ni particles surfaces. Treating the same catalyst with $\mathrm{H}_{2}$, the conversion yield return to be about $40 \%$. After the catalyst is treated with $\mathrm{H}_{2} \mathrm{~S}\left(1 \%\right.$ in $\left.\mathrm{N}_{2}\right)$ for $0.5 \mathrm{~h}$, the methanation reaction proceeds with a methane conversion yield of $12 \%$ and the hydrogen reduction does not reactivate the catalyst activity. When the poisoning with $\mathrm{H}_{2} \mathrm{~S}$ is extended 
up to $4 \mathrm{~h}$, the catalyst results completely and irreversibly deactivated. Therefore, it is essential to provide the system with a suitable sulphur compounds adsorber before sending the feed gas to methanation.

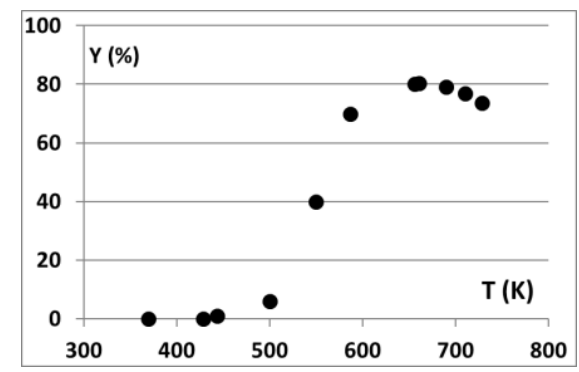

Fig. 2. Methane conversion yield.

The hydrogen production for the system described in section 2.2 has been investigated. More details on the adopted numerical approach can be found in [13] and [14]. The analysis is carried out by means of a lumped and distributed parameter model using the LMS AMESim software [20] and different approaches are selected for the simulated components. In particular multi and phase multi e component flow modelling is used to describe the behaviour of the combustion chamber and the heat exchangers. In the simulation, careful attention is paid in order to account for the accurate thermo-fluiddynamics properties of hydrogen and steam. The thermo-chemical databases available in [21] and [22] are used to calculate the fluid properties for the aluminium and alumina as well as for the hydrogen respectively. In the combustion chamber, the aluminium particles/droplets react with the water stream and a significant amount of heat is released and can be used for cogeneration purposes. In the numerical model no chemical kinetics or surface reactions are accounted for; thus, the heat release is calculated only on the basis of the global aluminium e water reaction (2). This reaction is thermodynamically favourable at reference standard state $\left(\mathrm{T}_{\text {std }}=298.15 \mathrm{~K} ; \mathrm{p}_{\text {std }}=1 \mathrm{~atm}\right)$ and it is also highly exothermic. Previous studies [23] demonstrated that above $753.15 \mathrm{~K}$ alumina is the most stable product, while if the temperature of the reaction is lower the most stable products are bayerite and boehmite which decrease the hydrogen yield and the heat release of the reaction; therefore this temperature is taken as a lower limit for the system operations. In the simulation the heat released by (2) is calculated assuming the reaction as instantaneous and under steady state conditions, i.e. the pressure within the combustion chamber is held constant and is determined by the thermo-fluid dynamics conditions of the system. Furthermore, the chemical efficiency of the reaction is taken as unity; nevertheless, the combustion efficiency is accounted for by introducing a certain amount of aluminium that does not react and therefore the relating heat is not released. The hydrogen production and energy conversion system propose in this paper can be used in the on-site production of hydrogen; instead of transporting fossil fuels, aluminium, either primary/secondary form or scrap aluminium, would be transported. From the analysis in the previous section it is possible to determine the amount of hydrogen produced each kilogram of aluminium and the thermal power output of the system obtained by oxidizing the aluminium. Figure 4 shows the hydrogen yield and thermal power production assuming a scale up of the reference unit of $1 \mathrm{MW}_{\text {th }}$. The new concept for the $\mathrm{CO}_{2}$ emission mitigation in the ceramic industry is based on the combined used of the systems described above. Figure 5 shows the schematic of the two systems as a retrofit for a reference industrial roller kiln for the ceramic industry. 


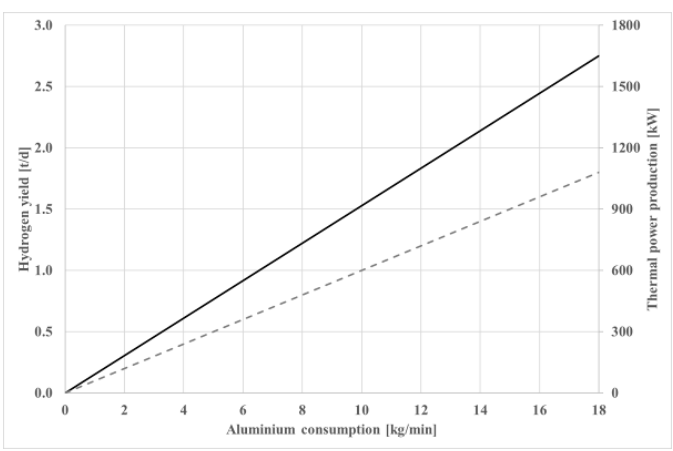

Fig. 4. Hydrogen and thermal power production.

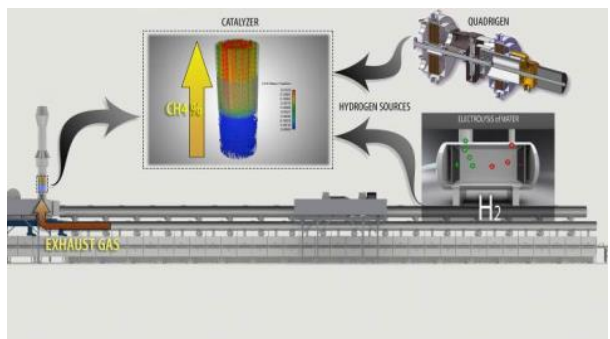

Fig. 5. Schematic of the $\mathrm{CO}_{2}$ methanation and hydrogen production systems combined to a ceramic kiln.

A CFD simulation of the Ni catalyst applied to the ceramic kiln exhaust stack is carried out by means of the BarracudaVR software [24]. The fluid domain focuses only on the catalyst as ideally could be installed in the exhaust chimney of the real kiln. The boundary conditions of the $3 \mathrm{D}$ simulation are derived from the lumped and distributed parameter model of the entire kiln as detailed in [25]. In addition to the Navier-Stokes equation and the energy equation, the equation for the chemical reactions taking place in the catalyst are accounted for. The flow rate composition of the exhaust stream is specified in terms of $\mathrm{CO}_{2}$ and $\mathrm{H}_{2} \mathrm{O}$ as the result of the stoichiometric combustion of the natural gas in the kiln's burners; $\mathrm{O}_{2}$ is also included to account for the excess air usually employed in the combustion and $\mathrm{N}_{2}$ is considered accordingly. The fumes mass flow rate and the temperature and the absolute pressure in the location where the catalyst can be installed are calculated with the numerical model of the entire kiln. Particular care is devoted to the methanation model and the equilibrium reaction (1) is assumed and the chemical kinetics described in [26] is adopted for its calculation. The geometry of the catalyst is created as a grid with a predefined spacing where the exhaust gases from the kiln can flow through. The hydrogen inlet is also considered in the fluid domain, thus the mixing of the reactants and the contact surface with the catalyst are accounted for in the analysis. The total height of the catalyst is $2 \mathrm{~m}$ and two different configurations of the exhaust inlet to the component are considered; one configuration is designed to determine a swirl motion of the flow and increase the mixing of the chemical species, while the second one has not effects on the flow pattern. More details about the modelling can in found in [27]. Figure 7 and 8 shows the velocity flow field and the $\mathrm{CH}_{4}$ distribution within the catalyst respectively. The beneficial effect of the exhaust gases swirl motion is evident in the methane distribution shown in Figure 8. This effect is also quantified in Figure 9, where the methane formation is plotted versus time until regime conditions are reached. The methane formation of the 
catalyst is remarkable and in the case of the swirl inlet configuration, it reaches approximately $40 \mathrm{Sm}^{3} / \mathrm{h}$ which correspond to $13 \%$ of the total natural gas consumption of the considered kiln. Therefore, an equivalent percentage of carbon dioxide is recovered and it is not emitted in atmosphere. For the simulated ceramic kiln the avoided annual $\mathrm{CO}_{2}$ emission can be estimated in $640 \mathrm{t} / \mathrm{y}$.

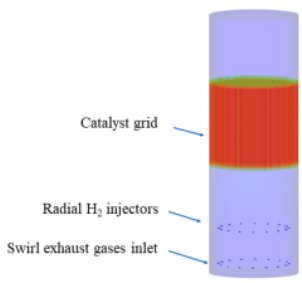

Fig. 6. Catalyst fluid domain.

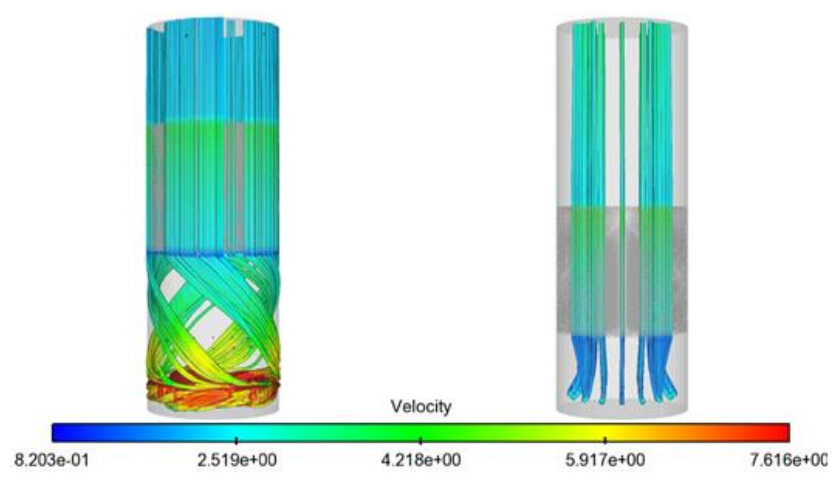

Fig. 7. Velocity flow field within the catalyst.

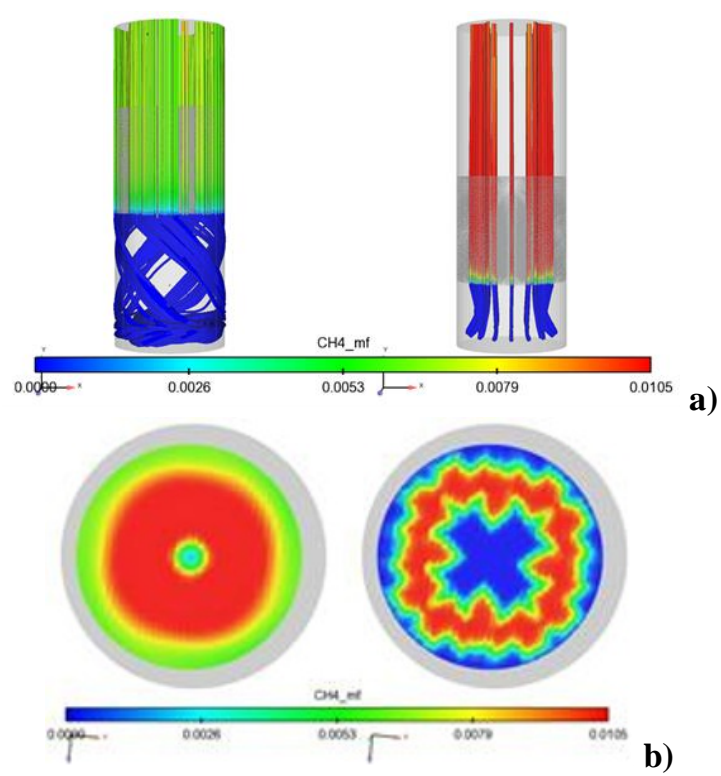

Fig. 8. $\mathrm{CH}_{4}$ distribution a) within the catalyst and b) on a cut section orthogonal to the catalyst axis. 


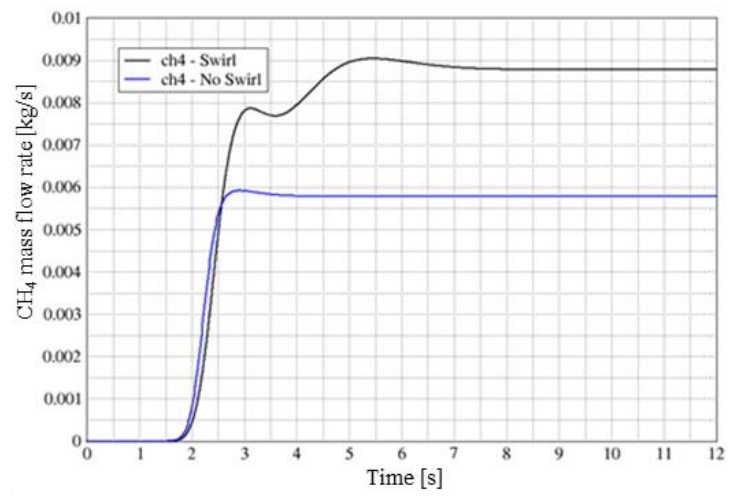

Fig. 9. $\mathrm{CH}_{4}$ formation as a function of time for the swirl and non-swirl configurations.

\section{Conclusion}

In this paper investigates a new concept for the carbon dioxide capture and reutilization has been investigated in the ceramic sector. The system is based on a Ni catalyst that converts the $\mathrm{CO}_{2}$ into methane using an external feed of hydrogen. The methane is then reused in the regular natural gas burners that equip the ceramic kiln. The performance of the catalyst have been analysed both by means of an experimental test rig and a numerical approach.

A novel concept for hydrogen production based on the combustion of aluminium and water is investigated for the hydrogen supply to the catalyst. Numerical simulation of the hydrogen production system demonstrated that the $\mathrm{H}_{2}$ yield is capable of covering the catalyst consumption for the ceramic kiln application. Furthermore, the hydrogen production can be increased by scaling up the considered unit.

Finally, the geometry of the catalyst has been proposed and its performance has been investigated by means of a CFD approach including the chemical reactions of the methanation process. The simulations demonstrated that the system can recover approximately $640 \mathrm{t} / \mathrm{y}$ of $\mathrm{CO}_{2}$ by producing $40 \mathrm{Sm}^{3} / \mathrm{h}$. This calculated methane production is close to the $13 \%$ of the total natural gas consumption of the entire kiln.

The Authors would like to acknowledge Mr. Federico Monterosso and Mr. Maurizio Lizzano for their important contribution to the present work.

\section{References}

1. C. Agrafiotis, T. Tsoutsos, Applied Thermal Engineering 21, 1231-1249 (2001)

2. M. D. Bovea, E. Diaz-Albo, A. Gallardo, F. J. Colomer, J. Serrano, Material and Design 31, 35-41 (2010)

3. J. Peng, Y. Zhao, L. Jiao, W. Zheng, L. Zeng, Energy Procedia 16, 467-476 (2012)

4. G. H. Watson, Methanation catalysts (Report number ICTIS/TR 09 IEA Coal Research, London, 1980)

5. V. Barbarossa, C. Bassano, P. Deiana, G. Vanga, $\mathrm{CO}_{2}$ conversion to $\mathrm{CH}_{4}$ (In: A Valuable Source of Carbon, Publisher: Springer-Verlag London, Editors: M. De Falco, G. Centi, G. Iaquaniello, 123-146, 2014)

6. P. Dupiano, D. Stamatis, E. L. Dreizin, International Journal of Hydrogen Energy 36, 8, 4781-4791 (2011) 
7. W.-Z. Gai, W.-H. Liu, Z.-Y. Deng, J.-G. Zhou, International Journal of Hydrogen Energy 37, 17, 13132-13140 (2012)

8. H. Nie, M. Schoenitz, E. L. Dreizin, International Journal of Hydrogen Energy 37, 15, 11035-11045 (2012)

9. S. S. Razavi-Tousi, J. A. Szpunar, International Journal of Hydrogen Energy 38, 2, 795-806 (2013)

10. M. S. Vlaskin, E. I. Shkolnikov, A. V. Bersh, A. Z. Zhuk, A. V. Lisicyn, A. I. Sorokovikov, Y. V. Pankina, Journal of Power Sources 196, 20, 8828-8835 (2011)

11. H.-W. Wang, H.-W. Chung, H.-T. Teng, G. Cao, International Journal of Hydrogen Energy 36, 23, 15136-15144 (2011)

12. F. Franzoni, M. Milani, L. Montorsi, Metal-Fueled Cogeneration Plant (Italian patent MO2008A000249, Sept. 2008. Extended to European patent PCT/EP2009/062334, Sept. 2009)

13. F. Franzoni, M. Milani, L. Montorsi, V. Golovitchev, Int. J. Hydrogen. Energ. 35, 1548 (2010)

14. F. Franzoni, M. Milani, S. Mercati, L. Montorsi, Int. J. Hydrogen. Energ. 36, 2803 (2011)

15. S. Mercati, M. Milani, L. Montorsi, F. Paltrinieri, Appl. Energ. 97, 686 (2012)

16. V. Barbarossa, G. Vanga, R. Viscardi, D. Mirabile Gattia, Energy Procedia 1, 45, 1325-1329 (2014)

17. D. E. Peebles, D. W. Goodman, J. M. White, J. Phys. Chem. 87, 4378-4387 (1983)

18. T. Szailer, E. Novak, A. Oszko', A. Erdohelyi, Top. Catal. 46, 1-2, 79-86 (2007)

19. J. Sehested, Catal. Today 111, 103-110 (2006)

20. Simcenter AMESim v16, licensed by Siemens Industry Software NV

21. A. N. Syverud, Journal of Physical Chemistry 14, 1 (1985)

22. R. F. Kubin, L. L. Presley, Thermodynamic properties and Mollier chart for hydrogen from $300 \mathrm{~K}$ to 20,000 K (Washington D. C., Scientific and Technical Information Division, National Aeronautics and Space Administration, 1964)

23. J. P. Foote, B. R. Thompson, J. T. Lineberry, Combustion of aluminum with Steamfor underwater propulsion (In: Advances in chemical propulsion: science to technology, Arlington, Virginia, USA, Office of Naval Research, 154-67, 2001)

24. V. R. Barracuda, licensed by CPFD Software LLC

25. M. Milani, L. Montorsi, M. Stefani, M. Lizzano, R. Saponelli, J. Environ. Manage. 203, 1026-1037 (2017)

26. M. S. Duyar, A Study of Catalytic Carbon Dioxide Methanation Leading to the Development of Dual Function Materials for Carbon Capture and Utilization http://academiccommons.columbia.edu/catalog/ac\%3A188052

27. R. Sanponelli, Metodologie innovative per l'analisi e la progettazione di sistemi industriali complessi (Ph.D Thesis for the Doctorate School in Industrial Innovation Engineering, University of Modena and Reggio Emilia, 2017) 